\title{
Effect of a hydro-alcoholic extract of Melissa officinalis on passive avoidance learning and memory
}

\author{
Zahra Dehbani $^{1,2}$, Alireza Komaki ${ }^{1{ }^{\mathbb{D}}}$, Farshid Etaee ${ }^{1,3}$, Siamak Shahidi ${ }^{1}$, Masoumeh Taheri ${ }^{1}$, Somayeh Komaki ${ }^{1}$, \\ Nafiseh Faraji ${ }^{1}$
}

${ }^{1}$ Neurophysiology Research Center, Hamadan University of Medical Sciences, Hamadan, Iran

${ }^{2}$ Department of Biology, Islamic Azad University of Hamadan, Hamadan, Iran

${ }^{3}$ Rahe Sabz Addiction Rehabilitation Clinic, Hamadan University of Medical Sciences, Hamadan, Iran

\section{A R T I C L E I N F O}

Article Type:

Original Article

Article History:

Received: 13 April 2018

Accepted: 25 January 2019

Keywords:

Melissa officinalis

Learning and memory

Herbals

Passive avoidance

Rat

Antioxidant

\begin{abstract}
A B S T R A C T
Introduction: Melissa officinalis (MO) or lemon balm is traditionally used as a sedative and anti-spasm herbal medicine. There is also evidence that this plant has effects on learning and memory. This study examined the effect of a hydro-alcoholic extract of MO on passive avoidance learning (PAL) and memory in male rats.

Methods: A total of 40 adult male Wistar rats were randomly distributed into four groups (200 to $220 \mathrm{~g} ; \mathrm{n}=10$ per group); three dose groups $(50,100$, and $200 \mathrm{mg} / \mathrm{kg}$ of the hydro-alcoholic extract of MO) and vehicle control (saline) group. Saline or doses of extract were administered daily for 14 days by oral gavage. The rats were trained to enter the shuttle box to record their behavior in the PAL task. A retrieval test was performed 24 hours following training.

Results: A significant difference was seen in performance among MO groups and the control. MO administered animals had a decreased number of acquisition trials $(P<0.05)$. In the retention task, $\mathrm{MO}$ administered animals had an increased step-through latency (SLT) $(P<0.01)$, and a decreased latency in the dark compartment $(P<0.001)$ compared to the control group.

Conclusion: The results of the study show that MO can improve learning and memory in the PAL task. Further investigation is needed to enhance our understanding of the neurobiological mechanisms of the MO extract and its effects on learning and memory.
\end{abstract}

Implication for health policy/practice/research/medical education:

The results of this study revealed that Melissa officinalis can enhance learning and memory in the passive avoidance test. The high levels of phenols and flavonoids in M. officinalis extracts may be responsible for its beneficial effects.

Please cite this paper as: Dehbani Z, Komaki A, Etaee F, Shahidi S, Taheri M, Komaki S, et al. Effect of a hydro-alcoholic extract of Melissa officinalis on passive avoidance learning and memory. J Herbmed Pharmacol. 2019;8(2):120-125. doi: 10.15171/ jhp.2019.19.

\section{Introduction}

Melissa officinalis (MO) or lemon balm is one of the most popular therapeutic plants (1). The origin of this plant is Europe, however, it is grown throughout the world (2). It belongs to the Lamiaceae family, which is known for many aromatic and medicinal plants, and commonly is used in European traditional medicine (1). Additionally, MO is a cultured lemon-scented herb, and it is used in common Chinese medicine as a tea for its sedation and anti-spasm impacts $(3,4)$. Due to its unique flavor, the food manufacturing also uses this plant to taste various foods (5). Also, MO is known for its antiviral, antioxidant, and anti-inflammatory therapeutic properties (6-8). Contemporary reports emphasize the sedative, antibacterial, and spasmolytic effects of MO, which indicate that it may improve certain disorders by reducing excitability, anxiety, and stress and improving sleep disturbance (3). Moreover, several studies suggest that $\mathrm{MO}$ is useful for treating a wide variety of other issues and diseases, such as HIV-1, some cancers, Alzheimer's disease (AD), hyperactivity disorder, indigestion, and hyperthyroidism (9-15). In addition to having soothing and carminative effects, $\mathrm{MO}$ acts as an anxiolytic and hypnotic (16). Immunostimulating effects of MO extract have also been demonstrated $(17,18)$. The aqueous extract of $\mathrm{MO}$ is enriched in phenolic compounds: rosmarinic, 
protocatechuic, caftaric, caffeic, ferulic, cichoric acids and flavonoid luteolin (19).

Traditional herbal medicine suggests the use of MO may improve memory and concentration (20). A recent study demonstrated that following a single-dose administration, this herb could modulate cognitive performance and mood in healthy young subjects (3). Moreover, MO enhances the quality of life in subjects who are struggling with severe dementia, and improves agitation (21). It is reportedly valuable in controlling $\mathrm{AD}$ and produces a particular impact on agitation in this patient population (2).

Therefore, MO may influence cognitive function. However, the effects of MO on passive avoidance learning (PAL) have not yet been described. The primary aim of our investigation was to test whether MO could improve rodent learning and memory in the PAL.

\section{Materials and Methods}

\section{Animals}

Forty male Wistar rats (200 to $220 \mathrm{~g}$ ) were obtained from the Razi Institute, Tehran, Iran. The rats were maintained in a room with a 12 -hour dark/light cycle at $22-25^{\circ} \mathrm{C}$, with 4 to 5 rats per cage. The rats had unrestricted access to food and water. Rodents were randomly distributed into four groups (10 per group); three dose groups (50,100 and $200 \mathrm{mg} / \mathrm{kg}$ of the hydro-alcoholic extract of MO) and vehicle control (saline) group. Saline or various doses of MO extract were administered daily for 14 days by oral gavage. All tests were performed in a soundproof room under the controlled light situation during the same time of day (within 11:00 AM to 3:00 PM) to diminish any confounding issues. All procedures were confirmed by the Veterinary Ethics Committee of the Hamadan University of Medical Science and were carried out based on the National Institutes of Health Guide for the Care and Use of Laboratory Animals (NIH Publication No. 85-23, revised 1985). The investigation timeline is displayed in Figure 1.

\section{Preparation of the extract}

The leaves of MO were gathered in spring and distinguished by the Botanic Institute of Hamadan University of Medical Sciences. Then, they were dried with airflow $\left(40^{\circ} \mathrm{C}\right)$, grounded, and then extracted with $70 \%$ ethanol. The extract was then dried in $40^{\circ} \mathrm{C}$ under vacuum condition, and subsequently freeze-dried $(22,23)$. Extract administrations were performed using aqueous suspensions of the dried extract.
Passive avoidance learning test

\section{PAL apparatus}

The PAL apparatus (shuttle box) included a light and a dark chamber with the same size $(30 \times 20 \times 20 \mathrm{~cm}$ each), with transparent and dark opaque plastic walls, respectively. The dark chamber had a grid floor, which elicited an electric current (Burj Sanat Co. Iran). An opaque door separated a rectangular opening between the two compartments.

\section{Passive avoidance training}

A subject rodent was located in the light chamber facing away from the guillotine door. After five seconds, the door was opened, and following the entrance of rat to the dark chamber, the door was closed, and an electrical shock (50$\mathrm{Hz}$ square wave, one $\mathrm{mA}$ for 1.5 seconds) was induced (2426). Afterward, 30 seconds later the animal was delivered to the cage. After two minutes, the animal was retested and if it did not enter the dark chamber in 120 seconds, successful acquisition of a passive avoidance behavior was reported $(27,28)$. The number of trials to the acquisition was reported as a measurement of learning $(29,30)$.

\section{Retention test}

The retention test was conducted 24 hours following PAL acquisition $(27,31-33)$. The animals were located in the light chamber, similar to PAL acquisition, and after five seconds, the door was lifted, and the latency to enter the dark chamber (step-through latency; STL) and time spent in the dark chamber (TDC) were reported for up to 300 seconds. If the animal did not enter the dark side in 300 seconds, the retention test was ended, and the maximum score of 300 seconds was reported.

\section{Statistical analysis}

All results are expressed as a mean \pm standard error of the mean (SEM) and processed with SPSS version 22. Data were analyzed using a one-way analysis of variance (ANOVA), followed by a Tukey post hoc analysis. Significance was set to $P<0.05$.

\section{Results}

The effects of Melissa officinalis on PAL acquisition Significant differences were seen between the vehicle and drug groups in the number of acquisition trials needed to have the criterion of 120 seconds in the light chamber (Figure 2). All groups administered MO (50, 100, and

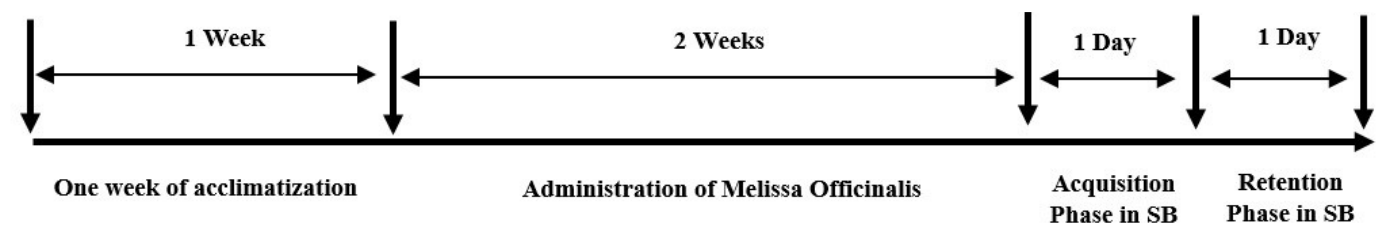

Figure 1. Timeline of experiments. 
$200 \mathrm{mg} / \mathrm{kg}$ ) required significantly fewer trials to reach criterion than the vehicle group $(P<0.05)$.

The effects of Melissa officinalis on the step-through latency

There were significant differences in the STL, 24 hours after the training, between the vehicle and MO groups (Figure 3). The STLs for the $50 \mathrm{mg} / \mathrm{kg}(P<0.01)$ and $200 \mathrm{mg} / \mathrm{kg}(P<0.05)$ groups were significantly greater in comparison with the vehicle. In particular, the STL for the $50 \mathrm{mg} / \mathrm{kg}$ group was significantly greater than the rest of the test groups $(P<0.05)$. Significant differences were not detected between the STL for the $100 \mathrm{mg} / \mathrm{kg}$ group in comparison with the vehicle group $(P>0.05)$.

The effects of Melissa officinalis on time spent in the dark compartment (TDC)

TDCs for all the MO groups (50, 100, and $200 \mathrm{mg} / \mathrm{kg}$ ) were significantly smaller than that of the vehicle group $(P<0.001, P<0.01, P<0.05$, sequentially). The TDC for the $50 \mathrm{mg} / \mathrm{kg}$ rats was significantly smaller than the 200 $\mathrm{mg} / \mathrm{kg}$ rats $(P<0.05)($ Figure 4$)$.

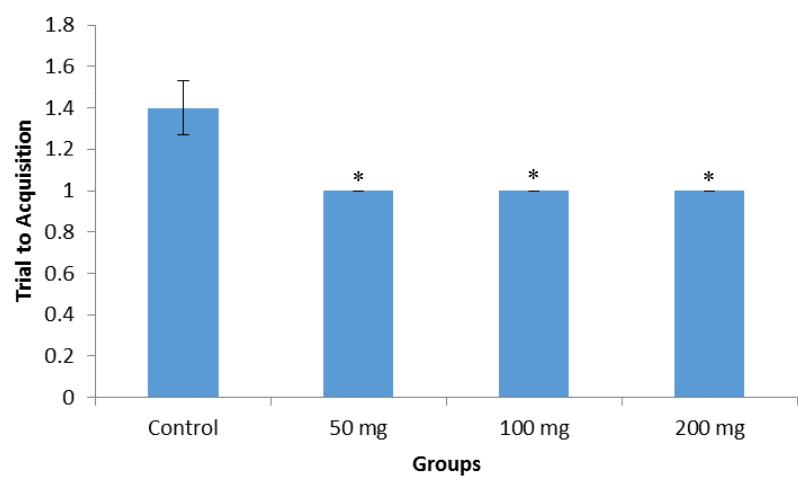

Figure 2. The impact of sub chronic oral gavage of Melissa officinalis extract $\left(50,100\right.$, and $200 \mathrm{mg} / \mathrm{kg}$ ) on the number of acquisition trials. ${ }^{*} P<$ 0.05 , significant differences between drug groups and vehicle $(n=10$ per groups).

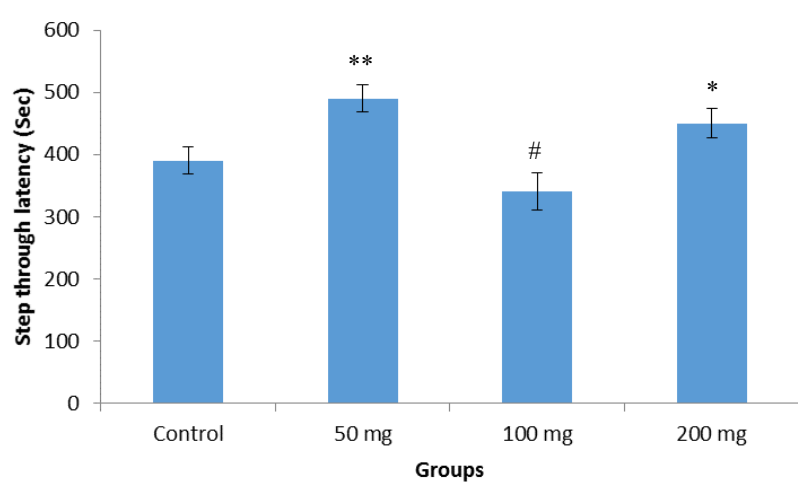

Figure 3. The effect of subchronic administration of Melissa officinalis extract $(50,100$, and $200 \mathrm{mg} / \mathrm{kg})$ on the step-through latency (STL) in the 24-h retention test. ${ }^{*} P<0.05$ and ${ }^{* *} P<0.01$ show significant differences between drug groups and vehicle. \# $P<0.05$ indicates significant differences between 50 and $200 \mathrm{mg} / \mathrm{kg}$ groups.

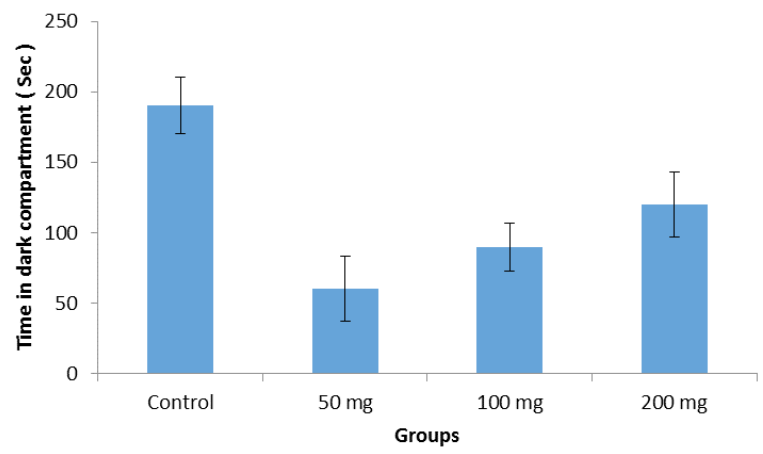

Figure 4. Effect of subchronic administration of various doses of Melissa officinalis extract $(50,100$, and $200 \mathrm{mg} / \mathrm{kg})$ on the time spent in the dark chamber (TDC) in the 24 -h retention test. ${ }^{*} P<0.05,{ }^{* *} P<0.01$ and ${ }^{* * *} P<0.001$ indicate significant differences between drug group and vehicle. \# $P<0.05$ shows significant differences in comparison with the $200 \mathrm{mg} / \mathrm{kg}$ group.

\section{Discussion}

This study revealed that subchronic oral administration of the hydro-alcoholic extract of $\mathrm{MO}$ improved PAL learning and memory. There was a significant impact of $\mathrm{MO}$ on the number of trials required for PAL acquisition. In addition, there was a significant improvement in the STL and a significant reduction in the TDC during the 24-hour retention testing.

These data suggest that $\mathrm{MO}$ can improve learning in normal healthy rats. However, this effect is not dosedependent. It previously reported that animals receiving $400 \mathrm{mg} / \mathrm{kg}$ of extract did not show improvement in maze performance (19). Several clinical studies using lemon balm have supported the use of MO for improvement in cognitive function $(3,20)$. These clinical studies showed a dose-dependent, time-dependent, and responsedependent relationship in regards to its effects on memory and mood (20).

There is increasing evidence for the possible efficacy of $\mathrm{MO}$ in the management of $\mathrm{AD}(34,35)$. In one clinical study, patients with mild to moderate $\mathrm{AD}$ who were administrated MO extract experienced significant cognitive benefits after 16 weeks of treatment (2).

The main components of MO are triterpene acids (e.g., ursolic acid), flavonoids (e.g., luteolin), and hydroxycinnamic acid derivatives, (e.g., rosmarinic acids) $(36,37)$. Additional notable compounds, recognized in this extract, were p-hydroxybenzoic acid and protocatechuic acid. MO extracts also have a considerable amount of caffeic acid derivatives, such as salvianolic acid (a caffeic acid trimer) (38). Finally, others have shown that linalool, citronellol, citronellal, and geranial are major chemical components in essential MO oil (39).

It has been reported that antioxidant activity can improve learning and memory $(40,41)$. Previous data suggest that MO contains high condensation of antioxidants (42-45). The antioxidant activity of plants could be due to their phenolic compounds $(27,46,47)$. MO has been shown 
to have a high phenolic portion as well as antioxidant properties (48). MO extract contains a number of monoterpenoid aldehydes, monoterpene glycosides, polyphenolic compounds (most notably, rosmarinic acid), and flavonoids (49). Caffeic acid, and rosmarinic acid have been reported to have antioxidant properties in vitro (45, 50-52). Additionally, the antioxidant activity of MO may provide some protection against the destructive effects of free radicals in dementia $(3,50)$. Ursolic acid can enhance age-related cognitive deficits through activation of antioxidant enzymes and reduction of lipid peroxidation (53). Moreover, MO demonstrated antioxidant activity via prevention of linoleic acid autoxidation (54). Finally, others have demonstrated that the cytoprotective effect of MO extracts in rats was, in particular, due to its freeradical scavenging properties $(18,44)$.

Furthermore, it has been shown that $\mathrm{MO}$ is active at the acetylcholine receptors in the central nervous system, modulating both ionotropic and metabotropic receptors, and following acute administration modulates mood and cognitive performance $(3,55)$. This issue raises the possibility of benefits of $\mathrm{MO}$ in attenuation of aging-related cholinergic decrements, as well as in improving states of delirium, such as those associated with anticholinergic drugs (56). The anticholinesterase activity of $\mathrm{MO}$ extract and its primary constituent, rosmarinic acid, has been reported previously (57). In addition, chlorogenic acid inhibits cholinesterase activity and ameliorates scopolamine-induced amnesia (58). The results of previous studies suggest that MO has cholinergic receptor-binding properties, and consumption of a single dose of MO can regulate both the mood and cognitive performance of the healthy young applicants (20).

\section{Conclusion}

MO can improve learning and memory in the PAL task. The high levels of phenols and flavonoids in MO extract may be responsible for its favorable impacts of $\mathrm{MO}$ on learning and memory. Nevertheless, the precise mechanism and active compounds implicated in cognitive improvement have not been fully characterized. Therefore, further biochemical and pharmacological studies are warranted.

\section{Acknowledgements}

The authors would like to express their gratitude to the staff of the Neurophysiology Research Center for their help in carrying out this project.

\section{Authors' contributions}

AK designed, analyzed the data and revised the manuscript. ZD was responsible for performing the experimental work. MT provided assistance for study design. SK and NF participated in plant extraction and all animal intervention. SS and FE participated in the draft preparation. The paper has been read and approved by all authors for publication.

\section{Conflict of interests}

The authors declare no conflict of interest.

\section{Ethical considerations}

All procedures were approved by the ethics committee of Hamadan University of Medical Sciences (IR.UMSHA. REC.1394.576). Ethical issues have been observed by the authors.

\section{Funding/Support}

This research was supported by a grant (Grant number: 9112154596) from the Hamadan University of Medical Sciences, Hamadan, Iran.

\section{References}

1. Najafian S, Rowshan V. Polyphenolic compounds of Mentha longifolia and Lemon balm (Melissa officinalis L.) in Iran. Int Res J Appl Basic Sci. 2013;4(3):608-12.

2. Akhondzadeh S, Noroozian M, Mohammadi M, Ohadinia S, Jamshidi AH, Khani M. Melissa officinalis extract in the treatment of patients with mild to moderate Alzheimer's disease: a double blind, randomised, placebo controlled trial. J Neurol Neurosurg Psychiatry. 2003;74(7):863-6.

3. Kennedy DO, Scholey AB, Tildesley NT, Perry EK, Wesnes KA. Modulation of mood and cognitive performance following acute administration of Melissa officinalis (lemon balm). Pharmacol Biochem Behav. 2002;72(4):953-64.

4. Kumar H, More SV, Han SD, Choi JY, Choi DK. Promising therapeutics with natural bioactive compounds for improving learning and memory--a review of randomized trials. Molecules. 2012;17(9):10503-39. doi: 10.3390/ molecules 170910503.

5. Wheatley D. Medicinal plants for insomnia: a review of their pharmacology, efficacy and tolerability. J Psychopharmacol. 2005;19(4):414-21.doi:10.1177/0269881105053309.

6. Borkowski B, Biesiadecka A, Litwinska B. Comparison of virusestatic activity of caffeic, chlorogenic and rosmarinic acids. Herba Pol. 1996;42(4):317-21.

7. Lamaison JL, Petitjean-Freytet C, Carnat A. [Medicinal Lamiaceae with antioxidant properties, a potential source of rosmarinic acid]. Pharm Acta Helv. 1991;66(7):185-8.

8. Vogt HJ, Tausch I, Wolbling RH, Kaiser PM. Melissenextrakt beiHerpes simplex. Der Allgemeinarzt. 1991;13:832-41.

9. Yamasaki K, Nakano M, Kawahata T, Mori H, Otake T, Ueba N, et al. Anti-HIV-1 activity of herbs in Labiatae. Biol Pharm Bull. 1998;21(8):829-33.

10. Geuenich S, Goffinet C, Venzke S, Nolkemper S, Baumann I, Plinkert $\mathrm{P}$, et al. Aqueous extracts from peppermint, sage and lemon balm leaves display potent anti-HIV-1 activity by increasing the virion density. Retrovirology. 2008;5:27. doi: 10.1186/1742-4690-5-27.

11. Hossain MA, Kim S, Kim KH, Lee SJ, Lee H. Flavonoid compounds are enriched in lemon balm (Melissa officinalis) leaves by a high level of sucrose and confer increased antioxidant activity. HortScience. 2009;44(7):1907-13. doi: 10.21273/hortsci.44.7.1907.

12. Kennedy DO, Little W, Haskell CF, Scholey AB. Anxiolytic effects of a combination of Melissa officinalis and Valeriana officinalis during laboratory induced stress. Phytother Res. 
2006;20(2):96-102. doi: 10.1002/ptr.1787.

13. Kennedy DO, Little W, Scholey AB. Attenuation of laboratory-induced stress in humans after acute administration of Melissa officinalis (Lemon Balm). Psychosom Med. 2004;66(4):607-13. doi: 10.1097/01. psy.0000132877.72833.71.

14. Muller SF, Klement S. A combination of valerian and lemon balm is effective in the treatment of restlessness and dyssomnia in children. Phytomedicine. 2006;13(6):383-7. doi: $10.1016 /$ j.phymed.2006.01.013.

15. de Sousa AC, Alviano DS, Blank AF, Alves PB, Alviano CS, Gattass CR. Melissa officinalis L. essential oil: antitumoral and antioxidant activities. J Pharm Pharmacol. 2004;56(5):677-81. doi: 10.1211/0022357023321.

16. Schulz V, Hansel R, Tyler VE. Rational phytotherapy: a physician's guide to herbal medicine. Psychology Press; 2001.

17. Drozd J, Anuszewska E. The effect of the Melissa officinalis extract on immune response in mice. Acta Pol Pharm. 2003;60(6):467-70.

18. Ulbricht C, Brendler T, Gruenwald J, Kligler B, Keifer $\mathrm{D}$, Abrams TR, et al. Lemon balm (Melissa officinalis L.): an evidence-based systematic review by the Natural Standard Research Collaboration. J Herb Pharmacother. 2005;5(4):71-114.

19. Ramanauskiene K, Raudonis R, Majiene D. Rosmarinic acid and Melissa officinalis extracts differently affect glioblastoma cells. Oxid Med Cell Longev. 2016;2016:1564257. doi: 10.1155/2016/1564257.

20. Kennedy DO, Wake G, Savelev S, Tildesley NT, Perry EK, Wesnes KA, et al. Modulation of mood and cognitive performance following acute administration of single doses of Melissa officinalis (Lemon balm) with human CNS nicotinic and muscarinic receptor-binding properties. Neuropsychopharmacology. 2003;28(10):1871-81. doi: 10.1038/sj.npp.1300230.

21. Ballard CG, O’Brien JT, Reichelt K, Perry EK. Aromatherapy as a safe and effective treatment for the management of agitation in severe dementia: the results of a double-blind, placebo-controlled trial with Melissa. J Clin Psychiatry. 2002;63(7):553-8.

22. Asami DK, Hong YJ, Barrett DM, Mitchell AE. Comparison of the total phenolic and ascorbic acid content of freezedried and air-dried marionberry, strawberry, and corn grown using conventional, organic, and sustainable agricultural practices. J Agric Food Chem. 2003;51(5):1237-

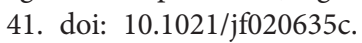

23. Silva LF, Lima ES, Vasconcellos MC, Aranha ES, Costa DS, Mustafa EV, et al. In vitro and in vivo antimalarial activity and cytotoxicity of extracts, fractions and a substance isolated from the Amazonian plant Tachia grandiflora (Gentianaceae). Mem Inst Oswaldo Cruz. 2013;108(4):5017. doi: 10.1590/s0074-02762013000400017.

24. Khodamoradi N, Komaki A, Salehi I, Shahidi S, Sarihi A. Effect of vitamin E on lead exposure-induced learning and memory impairment in rats. Physiol Behav. 2015;144:90-4. doi: 10.1016/j.physbeh.2015.03.015.

25. Ganji A, Salehi I, Nazari M, Taheri M, Komaki A. Effects of Hypericum scabrum extract on learning and memory and oxidant/antioxidant status in rats fed a long-term high-fat diet. Metab Brain Dis. 2017;32(4):1255-65. doi: 10.1007/ s11011-017-0022-4.

26. Shiri M, Komaki A, Oryan S, Taheri M, Komaki H, Etaee F. Effects of cannabinoid and vanilloid receptor agonists and their interaction on learning and memory in rats. Can J Physiol Pharmacol. 2017;95(4):382-7. doi: 10.1139/cjpp2016-0274.

27. Rezvani-Kamran A, Salehi I, Shahidi S, Zarei M, Moradkhani S, Komaki A. Effects of the hydroalcoholic extract of Rosa damascena on learning and memory in male rats consuming a high-fat diet. Pharm Biol. 2017;55(1):2065-73. doi: 10.1080/13880209.2017.1362010.

28. Zarrinkalam E, Ranjbar K, Salehi I, Kheiripour N, Komaki A. Resistance training and hawthorn extract ameliorate cognitive deficits in streptozotocin-induced diabetic rats. Biomed Pharmacother. 2018;97:503-10. doi: 10.1016/j. biopha.2017.10.138.

29. Komaki A, Karimi SA, Salehi I, Sarihi A, Shahidi S, Zarei M. The treatment combination of vitamins $\mathrm{E}$ and $\mathrm{C}$ and astaxanthin prevents high-fat diet induced memory deficits in rats. Pharmacol Biochem Behav. 2015;131:98-103. doi: 10.1016/j.pbb.2015.02.008.

30. Barzegar S, Komaki A, Shahidi S, Sarihi A, Mirazi N, Salehi I. Effects of cannabinoid and glutamate receptor antagonists and their interactions on learning and memory in male rats. Pharmacol Biochem Behav. 2015;131:87-90. doi: 10.1016/j. pbb.2015.02.005.

31. Asadbegi M, Yaghmaei P, Salehi I, Komaki A, EbrahimHabibi A. Investigation of thymol effect on learning and memory impairment induced by intrahippocampal injection of amyloid beta peptide in high fat diet- fed rats. Metab Brain Dis. 2017;32(3):827-39. doi: 10.1007/s11011017-9960-0.

32. Zarrinkalam E, Heidarianpour A, Salehi I, Ranjbar K, Komaki A. Effects of endurance, resistance, and concurrent exercise on learning and memory after morphine withdrawal in rats. Life Sci. 2016;157:19-24. doi: 10.1016/j. lfs.2016.05.034.

33. Moradkhani S, Salehi I, Abdolmaleki S, Komaki A. Effect of Calendula officinalis hydroalcoholic extract on passive avoidance learning and memory in streptozotocininduced diabetic rats. Anc Sci Life. 2015;34(3):156-61. doi: 10.4103/0257-7941.157160.

34. Perry EK, Pickering AT, Wang WW, Houghton P, Perry NS. Medicinal plants and Alzheimer's disease: integrating ethnobotanical and contemporary scientific evidence. J Altern Complement Med. 1998;4(4):419-28. doi: 10.1089/ acm.1998.4.419.

35. Perry EK, Pickering AT, Wang WW, Houghton PJ, Perry NS. Medicinal plants and Alzheimer's disease: from ethnobotany to phytotherapy. J Pharm Pharmacol. 1999;51(5):527-34.

36. Soodi M, Naghdi N, Hajimehdipoor H, Choopani S, Sahraei E. Memory-improving activity of Melissa officinalis extract in naive and scopolamine-treated rats. Res Pharm Sci. 2014;9(2):107-14.

37. Patora J, Klimek B. Flavonoids from lemon balm (Melissa officinalis L., Lamiaceae). Acta Pol Pharm. 2002;59(2):13943.

38. Miron TL, Herrero M, Ibanez E. Enrichment of antioxidant 
compounds from lemon balm (Melissa officinalis) by pressurized liquid extraction and enzyme-assisted extraction. J Chromatogr A. 2013;1288:1-9. doi: 10.1016/j. chroma.2013.02.075.

39. Norouzi M, Soleimani T, Zanousi MP. Essential oil component in leaf and flower of Lemon balm (Melissa officinalis L.). Res Pharm Sci. 2012;7(5):S749.

40. Cioanca O, Hritcu L, Mihasan M, Hancianu M. Cognitiveenhancing and antioxidant activities of inhaled coriander volatile oil in amyloid beta (1-42) rat model of Alzheimer's disease. Physiol Behav. 2013;120:193-202. doi: 10.1016/j. physbeh.2013.08.006.

41. George A, Ng CP, O'Callaghan M, Jensen GS, Wong HJ. In vitro and ex-vivo cellular antioxidant protection and cognitive enhancing effects of an extract of Polygonum minus Huds (Lineminus) demonstrated in a Barnes Maze animal model for memory and learning. BMC Complement Altern Med. 2014;14:161. doi: 10.1186/1472-6882-14-161.

42. Dimpfel W, Pischel I, Lehnfeld R. Effects of lozenge containing lavender oil, extracts from hops, lemon balm and oat on electrical brain activity of volunteers. Eur J Med Res. 2004;9(9):423-31.

43. Dragland S, Senoo H, Wake K, Holte K, Blomhoff R. Several culinary and medicinal herbs are important sources of dietary antioxidants. J Nutr. 2003;133(5):1286-90. doi: 10.1093/jn/133.5.1286.

44. Khayyal MT, el-Ghazaly MA, Kenawy SA, Seif-el-Nasr M, Mahran LG, Kafafi YA, et al. Antiulcerogenic effect of some gastrointestinally acting plant extracts and their combination. Arzneimittelforschung. 2001;51(7):545-53. doi: 10.1055/s-0031-1300078.

45. Triantaphyllou K, Blekas G, Boskou D. Antioxidative properties of water extracts obtained from herbs of the species Lamiaceae. Int J Food Sci Nutr. 2001;52(4):313-7.

46. Cook NC, Samman S. Flavonoids--Chemistry, metabolism, cardioprotective effects, and dietary sources. J Nutr Biochem. 1996;7(2):66-76.doi:10.1016/S0955-2863(95)00168-9.

47. Ganji A, Salehi I, Sarihi A, Shahidi S, Komaki A. Effects of Hypericum Scabrum extract on anxiety and oxidative stress biomarkers in rats fed a long-term high-fat diet. Metab Brain Dis. 2017;32(2):503-11. doi: 10.1007/s11011016-9940-9.

48. Ivanova D, Gerova D, Chervenkov T, Yankova T. Polyphenols and antioxidant capacity of Bulgarian medicinal plants. J Ethnopharmacol. 2005;96(1-2):145-50. doi: 10.1016/j. jep.2004.08.033.

49. Mulkens A, Stephanou E, Kapetenadis I. Heterosides a genines volatiles dans les feuilles de Melissa officinalis L.(lamiaceae). Pharm Acta Helv. 1985;60(9):276-8.

50. Hohmann J, Zupko I, Redei D, Csanyi M, Falkay G, Mathe I, et al. Protective effects of the aerial parts of Salvia officinalis, Melissa officinalis and Lavandula angustifolia and their constituents against enzyme-dependent and enzyme-independent lipid peroxidation. Planta Med. 1999;65(6):576-8. doi: 10.1055/s-2006-960830.

51. Englberger W, Hadding U, Etschenberg E, Graf E, Leyck S, Winkelmann J, et al. Rosmarinic acid: a new inhibitor of complement C3-convertase with anti-inflammatory activity. Int J Immunopharmacol. 1988;10(6):729-37.

52. Peake PW, Pussell BA, Martyn P, Timmermans V, Charlesworth JA. The inhibitory effect of rosmarinic acid on complement involves the C5 convertase. Int J Immunopharmacol. 1991;13(7):853-7.

53. Lu J, Zheng YL, Wu DM, Luo L, Sun DX, Shan Q. Ursolic acid ameliorates cognition deficits and attenuates oxidative damage in the brain of senescent mice induced by D-galactose. Biochem Pharmacol. 2007;74(7):1078-90. doi: 10.1016/j.bcp.2007.07.007.

54. Marongiu B, Porcedda S, Piras A, Rosa A, Deiana M, Dessi MA. Antioxidant activity of supercritical extract of Melissa officinalis subsp. officinalis and Melissa officinalis subsp. inodora. Phytother Res. 2004;18(10):789-92. doi: 10.1002/ ptr.1549.

55. Wake G, Court J, Pickering A, Lewis R, Wilkins R, Perry E. CNS acetylcholine receptor activity in European medicinal plants traditionally used to improve failing memory. J Ethnopharmacol. 2000;69(2):105-14.

56. Ashton H. Delirium and hallucinations. Advances in Consciousness Research. 2002;36:181-204.

57. Dastmalchi K, Ollilainen V, Lackman P, Boije af Gennas G, Dorman HJ, Jarvinen PP, et al. Acetylcholinesterase inhibitory guided fractionation of Melissa officinalis L. Bioorg Med Chem. 2009;17(2):867-71. doi: 10.1016/j. bmc.2008.11.034.

58. Kwon SH, Lee HK, Kim JA, Hong SI, Kim HC, Jo TH, et al. Neuroprotective effects of chlorogenic acid on scopolamineinduced amnesia via anti-acetylcholinesterase and antioxidative activities in mice. Eur J Pharmacol. 2010;649(13):210-7. doi: 10.1016/j.ejphar.2010.09.001. 